\title{
$O$ TodoDia e a comunidade: o jornal regional como instrumento de cidadania
}

\author{
Ivone Moreira da Silva * \\ Bruno Fuser **
}

\section{Resumo}

Este trabalho apresenta os resultados de pesquisa realizada com integrantes de diversos segmentos sociais sobre a relação entre o jornal TodoDia e seus leitores, com ênfase na importância da publicação como elemento de formação de uma consciência crítica e como instrumento de manifestação da comunidade local e regional. O objetivo é levantar em que medida as comunidades de Americana, Santa Bárbara d'Oeste, Sumaré, Hortolândia, Nova Odessa e Paulínia, no Interior de São Paulo, se identificam com o jornal, qual a importância do veículo para essas cidades, como a sociedade interfere no processo de pauta e qual a influência que exerce no jornal.

Palavras-chave: Jornalismo regional; jornalismo comunitário; informação e desenvolvimento regional

\section{Introdução}

O jornal TodoDia, ao ser criado, anunciou o compromisso de integrar cinco municípios da região de Americana por meio da informação. Regionalizar os debates, preservando as características e os fatos locais, é o que norteia a pauta do jornal. O objetivo central desta pesquisa é verificar de que maneira se dá a relação entre a sociedade e o jornal, como a comunidade influencia na produção jornalística, se os leitores se identificam nas páginas da publicação, de que maneira o jornal é utilizado como instrumento de transformação social e promoção da cidadania.

Para isso apresentamos os dados principais da história do jornal e de seu entorno, analisando, em seguida, alguns conceitos de jornalismo regional e poder local, nos quais se basearam as reflexões teóricas do estudo. Na seqüência relatamos as estratégias adotadas pelo TodoDia e

* Jornalista, especialista em Jornalismo e Segmentação Editorial pela PUC-Campinas.

** Jornalista, doutor em Ciências da Comunicação pela ECA/USP, professor titular da PUC-Campinas. E-mail: brunofuser@uol.com.br

Comun. Inf., v. 7, n. 1, p.141-155, jan./jun. 2004 
um pouco da rotina do jornal, além de apresentar algumas das principais reportagens e campanhas feitas pelo veículo. Finalmente, destacamos o resultado da pesquisa qualitativa feita com integrantes de diversos segmentos da sociedade, mostrando como a comunidade avalia o trabalho, a influência e o envolvimento do jornal nos diferentes setores sociais, e desenvolvemos reflexões a respeito das informações obtidas.

Para avaliar o papel do TodoDia na comunidade da região de Americana foram entrevistados para esta pesquisa: o diretor do Sindicato dos Trabalhadores Têxteis de Americana, Antônio Martins; o vice-presidente da Federação Paulista das Associações de Moradores de São Paulo e presidente do Consab's (Conselho das Associações de Moradores de Sumaré), José Adilson Pereira dos Santos; o padre Itamar Gonçalves, da Paróquia São Domingos, de Americana; os presidentes das Câmaras de Vereadores de Americana, Celso Zoppi (PT), e de Hortolândia, Lenivaldo Pauliuki (PSDB); os presidentes das associações comerciais, industriais e agrícolas de Sumaré, Raul Camargo, de Americana, Nilsa Tavoloni, e de Hortolândia, Tercio Mascarenhas; o delegado seccional de Americana, Paulo Jodas; o prefeito de Sumaré e ex-vice-presidente do Conselho de Desenvolvimento da Região Metropolitana de Campinas, Dirceu Dalben (PPS); os vice-prefeitos de Nova Odessa, Luciano Dormiciano (PDT), e de Hortolândia, Walter Bernardo (PSDB); o deputado federal Francisco Sardelli (PFL); o deputado estadual Vanderlei Macris (PSDB); e o secretário de Educação e Cultura de Americana, Herb Carlini. Ainda foram entrevistados, do jornal ou da empresa responsável pelo TodoDia: Roberto Romi Zanaga, diretor-presidente da Editora Z, que edita o jornal; Sérgio La Luna, diretor comercial do TodoDia; Delvio Antônio Nunes, diretor de redação; e Cláudio Gioria, editorexecutivo e editor de esportes do TodoDia.

Apesar de o jornal circular em 14 cidades, foi feita a opção de limitar as cidades envolvidas na pesquisa, em função do curto período que o jornal está circulando nas cidades de Artur Nogueira, Cosmópolis, Engenheiro Coelho, Holambra, Jaguariúna, Monte Mor, Pedreira e Santo Antonio de Posse.

As entrevistas foram realizadas com a técnica da entrevista semiestruturada, em que se utilizou um roteiro básico e, a partir das informações fornecidas pelo próprio entrevistado, buscava-se Comun. Inf., v. 7, n. 1, p.141-155, jan./jun. 2004 
aprofundar o tema. Os conceitos discutidos com os entrevistados centravam-se nos seguintes aspectos: o jornal como instrumento de integração dos municípios e da sociedade da região; o TodoDia como veículo participante na sociedade; ojornal como veículo que potencializa e atende as necessidades locais; o TodoDia como canal de debate e conhecimento das ações regionais e metropolitanas.

\section{A região e o TodoDia}

O jornal TodoDia circula em 14 cidades da Região Metropolitana de Campinas (RMC): Americana, Artur Nogueira, Cosmópolis, Engenheiro Coelho, Holambra, Hortolândia, Jaguariúna, Monte Mor, Nova Odessa, Paulínia, Pedreira, Santa Bárbara d'Oeste, Santo Antonio de Posse e Sumaré, totalizando uma área geográfica de 1.985,3 quilômetros quadrados. São 1.010.317 habitantes nas 14 cidades, segundo dados do último censo do Instituto Brasileiro de Estatísticas e Geografia (IBGE), realizado em 2000.

O TodoDia foi criado em 28 de outubro de 1996. Inicialmente, o jornal circulava em Americana, Santa Bárbara d'Oeste, Sumaré, Nova Odessa e Hortolândia. Em 11 de junho de 1999, a cidade de Paulínia foi incorporada à cobertura. Em 17 de setembro de 2002, o jornal passa a circular em mais oito cidades da RMC: Artur Nogueira, Cosmópolis, Engenheiro Coelho, Holambra, Jaguariúna, Monte Mor, Pedreira e Santo Antonio de Posse. O jornal é filiado ao IVC (Instituto Verificador de Circulação) e tem uma tiragem média de 14.613 exemplares1. No ranking do interior, medido pelo IVC em julho de 2002, o TodoDia aparece na $5^{\text {a }}$ posição de tiragem, ficando atrás do Correio Popular (Campinas), Cruzeiro do Sul (Sorocaba), Diário da Região (São José do Rio Preto) e Jornal de Piracicaba. No ranking estadual, o jornal está na $11^{\mathrm{a}}$ posição.

O TodoDia chega às bancas com o objetivo anunciado de integrar os cinco municípios por meio da informação. Localizado em Americana, o jornal tem a preocupação de dar o mesmo tratamento jornalístico para as cinco cidades. O veículo surge como a única mídia impressa voltada exclusivamente para aquelas cinco cidades, apesar de contar com cadernos de noticiário nacional e internacional.

Até então, os jornais que circulavam na região eram divididos basicamente em três perfis: jornais de grande porte com circulação

Comun. Inf., v. 7, n. 1, p.141-155, jan./jun. 2004 


\section{4}

regional, mas que raramente produziam matérias sobre essas cidades. Exemplos: Folha de S. Paulo e o Estado de S. Paulo. Jornais de caráter regional em nível de circulação, mas que não acompanham o dia-a-dia dessas cidades. Um exemplo é o Correio Popular. Ejornais locais, focados em uma cidade e que esporadicamente publicavam matérias de outras cidades. Exemplo: $O$ Liberal e Diário de $S$. Bárbara. O Tribuna Liberal, localizado em Sumaré, circulava em Sumaré, Hortolândia, Nova Odessa e Monte Mor, mas a cobertura privilegiava as cidades de Sumaré e Hortolândia. Hoje, circulam nas seis cidades que compreendem a análise deste trabalho dez jornais diários e semanais, mas que não circulam às segundas-feiras -, sete emissoras de rádio e duas TVs2 .

Cerca de 150 profissionais trabalham no TodoDia. Na redação são cinco editores, 14 repórteres, três fotógrafos, quatro diagramadores, um chargista, dois rádio-escuta e um auxiliar de redação, além de quatro colunistas sociais. O jornal também é distribuído nas principais bancas do Centro de Campinas.

\section{O jornal local como instrumento de transformação}

A importância do jornal local, ou regional, como instrumento de transformação, de consciência e de ação política, tem sido pouco discutida na academia, o que se pode creditar a vários motivos, um deles a grande concentração dos grupos de mídia no país. Tal concentração acaba por desviar, compreensivelmente, o foco das atenções para os jornais de maior circulação, mas tal perspectiva não deve obliterar por completo a análise de jornais locais e regionais no cenário brasileiro.

O conhecimento local como pressuposto para a ação política é ressaltado, por exemplo, por Ladislau Dowbor, para quem "a formação de uma geração de jovens, conhecedores do potencial de sua região e do seu município, pode constituir uma alavanca poderosa para a transformação social"' (DOWBOR, 1999:77).

Ao enfatizar e debater os problemas locais, o jornal amplia a discussão e convoca a comunidade a fazer parte da solução dos problemas. Na opinião de Dowbor, o envolvimento da população na discussão dos problemas é essencial para a busca das respectivas soluções. Quando conhece os problemas, a comunidade passa a ter mais autoridade para reivindicar medidas e cobrar respostas do poder público. Por outro Comun. Inf., v. 7, n. 1, p.141-155, jan./jun. 2004 
lado, o poder público deve levar em conta o ponto de vista da sociedade, porque é ela que conhece e convive com os problemas diários.

O professor Dirceu Fernandes Lopes, no texto "A Evolução do Jornalismo em São Paulo", avalia a importância dos veículos locais:

\begin{abstract}
"Ao contrário do leitor da Capital, que tem outros meios de informação sobre sua comunidade, o habitante do interior escolhe $o$ próprio jornal de sua cidade para saber o que ocorre ao seu redor, no seu mundo. É no jornal local que o morador busca e encontra, numa linguagem acessível e própria, aquilo que interessa para o seu diaa-dia" (LOPES, 1996).
\end{abstract}

Dirceu Fernandes Lopes ressalta ainda: "Nada substitui a visão local. Há um processo natural de identificação do leitor com o jornal de sua cidade, independente de sua linha editorial,jáqueé esse veículo que informa o que interessa mais de perto a seus leitores" (LOPES, 1996).

Ojornalismo regional contribui diretamente para a conscientização dos leitores. Cecília G.. C. Pavani, em seu artigo "Jornal regional: construção de cidadania", publicado pelo Correio Popular em novembro de 2002, faz uma análise da importância do jornalismo regional para a formação dos leitores. Ela afirma:

\begin{abstract}
"Entre os meios que se propõem a atualizar a educação e torná-la mais condizente com o que vivenciamos, está um que apostamos como ferramenta particularmente valiosa e tentadora: o jornal regional diário, de fácil acesso e de baixo custo se pensarmos em termos de material básico para reflexão, questionamento e formação de opinião de um cidadão na escola" (PAVANI, 2002:1).
\end{abstract}

A valorização da informação local pode ser observada no artigo "Jornalismo no Interior - potencialidades éticas e técnicas", apresentado na Intercom de 2002. O autor, Toni André Scharlau Vieira, destaca o interesse de jornais de destaque mundial, como o New York Times, de investir em cadernos regionais: "Até mesmo nos EUA se verifica que, do ponto de vista da identificação entre emissor e receptor os veículos locais crescem e se consolidam" (VIEIRA, 2002).

Toni André Scharlau Vieira também faz uma referência à proximidade maior que existe entre jornalistas de jornais do interior e

Comun. Inf., v. 7, n. 1, p.141-155, jan./jun. 2004 
o público receptor. Mais perto do jornal, a comunidade pode interferir de forma direta no trabalho da redação. No TodoDia, de acordo com a estimativa apresentada pelo diretor de redação, Delvino Antunes Nunes, $90 \%$ das pautas do "TodoDia nos Bairros" são solicitadas pelos moradores mediante telefonemas e cartas enviadas à redação. 3

\section{O jornalismo regional do TodoDia}

Integrar a região e valorizar os assuntos locais, respeitando as características de cada cidade, são duas das principais preocupações editoriais do TodoDia. O carro-chefe do jornal, o caderno de Cidades, é pautado em cima dos acontecimentos que movimentam os 14 municípios. Nas primeiras cidades onde se iniciou a cobertura e nas quais o jornal está consolidado existe uma coluna social para cada município. O veículo também trabalha com manchetes diferentes para grupos de cidades. Americana, Nova Odessa e Santa Bárbara d'Oeste recebem uma manchete ligada a essas cidades. Outra edição do jornal, com manchete diferente, é enviada a Sumaré, Hortolândia e Monte Mor. E uma terceira manchete é trabalhada para o jornal distribuído em Paulínia, Cosmópolis, Artur Nogueira, Engenheiro Coelho, Santo Antonio de Posse, Jaguariúna, Holambra e Pedreira.

Roberto Romi Zanaga, diretor-presidente da Editora Z, que edita o jornal TodoDia, explica o porquê e a importância do foco local agregado às notícias regionais: "O que é a regionalização se não é a união de núcleos que são municípios? E esses municípios têm suas vidas próprias, seus interesses. Então, quando você pensa dessa forma, você não tem como pegar e separar o que é regionalização do que é notícia local". ${ }^{4}$

O acompanhamento das informações locais pode ser percebido com a cobertura de sessões da Câmara de cada cidade. O jornal também privilegia a cobertura de eventos, que podem não despertar o mesmo interesse em toda a região, mas é importante para a população de determinada cidade, como as festas populares e religiosas.

\subsection{Foco local}

No TodoDia, cada cidade tem um repórter responsável pela cobertura. É esse repórter quem faz a checagem e a ronda diariamente das fontes, in loco. A pauta elaborada dentro do jornal orienta o repórter, mas como o TodoDia é responsável pela cohertura de 14 Comun. Inf., v. 7, n. 1, p.141-155, jan./jun. 2004 
cidades, cabe ao repórter de cada município fazer a checagem diária. As matérias são regionalizadas quando o jornal aborda determinada situação em todas as cidades de cobertura.

O diretor comercial do TodoDia, Sérgio La Luna, comenta sobre a preocupação do jornal em valorizar a informação regional, sem esquecer do foco local: "O meu leitor tem que sentir a informação regional, mas sentir-se privilegiado. Então, toda a comunicação que é feita com o leitoré feita com este pressuposto. Sempre que se faz alguma coisa, qualquer ação, qualquer estratégia de marketing, distribuição ou comunicação, devese levar em conta essa característica". 5

O jornal também incentiva e apóia eventos locais. "As pessoas procuram muito o veículo jornal. Por quê? Em geral, eles têm a idéia de um evento e rapidamente descobrem a necessidade de o evento ser divulgado", informa La Lula. Por mês, geralmente são feitos oito pedidos de apoio a evento. Metade dos pedidos é atendida.

Com relação aos aspectos comerciais, a vantagem do veículo regional éa redução de custos para o anunciante, que tem sua mídia veiculada em uma região formada por 14 cidades. La Luna ressalta que "o fato de ser regional permite que toda a administração do processo publicitário seja feita por um único canal, ao passo que no modelo tradicional você tem veículos limitados e vinculados a municípios. E você precisa planejar a mídia para cada um dos municípios, encaminhar uma autorização para cada um dos veículos e negociar preço com cada um dos veículos".

\subsection{Principais reportagens}

As reportagens apontadas pelos integrantes de diversos segmentos sociais como as mais importantes feitas pelo jornal são: a campanha que defendeu a isenção, aos moradores das cidades da região, da tarifa cobrada pelo pedágio instalado em Nova Odessa e a campanha Vote Regional, realizada nas eleições de 1998, para conscientizar a população sobre a importância de votar em candidatos locais.

Outras reportagens foram citadas pelos entrevistados como as mais importantes realizadas pelo jornal. Dentre elas estão a cobertura da Usina Termelétrica Carioba II, as reportagens feitas sobre segurança, como falta de viaturas e fugas de presos, e a denúncia de meninas que se prostituíam às margens da Rodovia SP-304, que liga a Rodovia

Comun. Inf., v. 7, n. 1, p.141-155, jan./jun. 2004 


\section{8}

Anhangüera a Piracicaba, sob o pretexto de vender suco de laranja. Carrinhos de suco ocultavam uma rede de prostituição infantil, que foi desmantelada após a denúncia do jornal. O delegado seccional de Americana, Paulo Jodas, afirma que "esta matéria motivou uma ação policial. Aquela matéria exigiu uma posição firme. E depois da matéria houve uma atuação da polícia. Nós tomamos providências depois das denúncias". ${ }^{6}$ Outra matéria que repercutiu na Região foi a que denunciou um show erótico para menores. A apresentação ocorreu em um dos clubes mais tradicionais de Americana. Adenúncia foi feita após uma exaustiva investigação da equipe de reportagem.

As reportagens referentes ao pedágio de Nova Odessa, publicadas entre dezembro de 2000 e maio de 2001, são destacadas por diversos entrevistados, envolvidos direta ou indiretamente na polêmica. Eles afirmam que o debate levado nas páginas do TodoDia influenciou a decisão, que poupou as cidades vizinhas de Nova Odessa da cobrança. O resultado motivou um editorial na capa do TodoDia, que considerou uma vitória a decisão, já que o jornal defende a integração da região. Foram produzidas 57 reportagens sobre o assunto.

"Como administrador público, avalio que as matérias foram excessivamente críticas, sem observar os problemas [causados pela rota de fuga e que, ao contrário do que o entrevistado disse, foram abordados pelo jornal]. Como cidadão, eu acho que o jornal fez uma boa cobertura porque mostrou soluções para um problema", avaliou o vice-prefeito de Nova Odessa, Luciano Domiciano (PDT). ${ }^{?}$

O vice-prefeito de Hortolândia, Walter Bernardo (PSDB), também acredita que o jornal teve um papel decisivo na definição da isenção da tarifa para as cidades vizinhas de Nova Odessa. "Essa matéria é um grande exemplo. Se não fosse o jornal batendo todos os dias, levantando a polêmica, não teríamos a isenção do pedágio".

O sucesso da campanha Vote Regional, realizada em 1998 pelo jornal, com o objetivo de conscientizar os eleitores sobre a necessidade de votar em candidatos da Região, com reportagens e campanha de marketing, é medido, dentre outros fatores, pelo número de deputados eleitos naquele ano. Nas eleições de 1998, a Região conseguiu eleger três deputados - um federal e dois estaduais. Dois candidatos assumiram depois de ficar na suplência. Até 1998, a Região contava com apenas um deputado estadual.

Comun. Inf., v. 7, n. 1, p.141-155, jan./jun. 2004 
"Eu acho que o leitor se conscientizou. E o start desse processo foi aquela divulgação em 1998", afirmou o deputado federal Francisco Sardelli (PFL), sobre a influência da campanha realizada pelo jornal em $1998^{\circ} \mathrm{A}$ presidente da Acia (Associação Comercial e Industrial de Americana), Nilza Tavoloni, assinalou que a campanha Vote Regional, feita em 1998, ajudou a aumentar a conscientização das pessoas em relação ànecessidade de votar em candidatos da Região. ${ }^{10}$

\section{O TodoDia e a comunidade}

Os conceitos sobre o TodoDia discutidos nas entrevistas, como se afirmou anteriormente, foram: o jornal como instrumento de integração dos municípios e da sociedade da Região; o TodoDia como veículo participante na sociedade; o jornal como veículo que potencializa e atende as necessidades locais; o TodoDia como canal de debate e conhecimento das ações regionais e metropolitanas. Apresentamos a seguir algumas das informações obtidas nas entrevistas:

\subsection{Instrumento de integração}

Ojornal TodoDia como veículo de integração entre os municípios da Região é um dos conceitos apontados pelos representantes das comunidades de Americana, Santa Bárbara d'Oeste, Sumaré, Nova Odessa, Paulínia e Hortolândia. Ao valorizar a informação local eregional, os segmentos da sociedade entendem que o jornal propicia uma aproximação entre as cidades, até porque os municípios passam a discutir os problemas comuns. "O jornal TodoDia, com a característica regional, nasce para interligar as informações de seis cidades", afirmou o deputado federal Francisco Sardelli (PFL). Sobre a integração entre os municípios, o deputado estadual Vanderlei Macris (PSDB) acrescentou: "Houve essa integração porque você começa a trazer informações comuns. Santa Bárbara, Sumaré e Hortolândia passaram a fazer a discussão política a partir das colocações do jornal". ${ }^{11}$

A informação regional, como apontou o secretário de Educação e Cultura de Americana, Herb Carlini, se transforma em um mecanismo de cobrança. "Essa tendência (jornalismo regional) permite que o leitor tenha padrões de comparação para comparar, por exemplo, a atuação do poder público em cada uma das cidades, em várias áreas". ${ }^{12} \mathrm{O}$ presidente da Câmara de Vereadores de Hortolândia, Lenivaldo Pauliuki Comun. Inf., v. 7, n. 1, p.141-155, jan./jun. 2004 
(PSDB), acredita que a informação regional propicia a integração dos municípios, que passam a aproveitar as idéias das cidades vizinhas. ${ }^{13}$

Para o presidente da Câmara de Vereadores de Americana, Celso Zoppi (PT), a informação regional propicia uma integração não só entre os poderes constituídos, mas também entre a própria sociedade organizada. ${ }^{14}$

\subsection{Veículo participante na sociedade}

O prefeito de Sumaré e ex-vice-presidente do Conselho de Desenvolvimento da Região Metropolitana de Campinas, Dirceu Dalben (PPS), enfatizou a participação do jornal TodoDia no crescimento das cidades que fazem parte da cobertura do jornal. "Nos últimos tempos, Sumaré cresceu muito e o TodoDia teve participação nesse crescimento porque ajudou as pessoas a se conscientizarem, mostrando os problemas da dengue, por exemplo". ${ }^{15} \mathrm{O}$ diretor primeiro-secretário do Sindicato dos Têxteis de Americana, Antonio Martins, explicou como o jornal atua diretamente nas causas dos trabalhadores: "Há cerca de um mês nós ficamos sabendo, através do jornal, de um acidente em uma fábrica, onde uma mulher perdeu o couro cabeludo. Foi uma informação que nós só ficamos sabendo através do TodoDia. Toda vez que temos novidades mandamos release, enviamos a denúncia e o jornal divulga o caso. Com a denúncia feita no jornal, muitas empresas ficam com vergonha e acabam chamando para negociar. Claro que tem aquelas empresas semvergonha, mas na maioria das vezes as empresas sentem vergonha quando essa notícia sai no jornal e nos chamam para conversar, isso ajuda muito". ${ }^{16}$

A campanha Vote Regional, realizada em 1998, é um exemplo de ação desenvolvida pelo jornal que teve reflexos positivos na sociedade. Com a campanha, os eleitores tiveram informações mais precisas e argumentos sobre a importância de votar em candidatos da Região. "Aquela campanha causou uma influência no processo eleitoral. As pessoas estão mais conscientes e passaram a votar mais nos candidatos da Região", afirma o presidente da Acias (Associação Comercial, Industrial e Agropecuária de Sumaré), Raul Camargo. ${ }^{17}$

\subsection{Olhar nas necessidades locais}

Um dos pontos positivos do TodoDia, enfatizados pela pesquisa Comun. Inf., v. 7, n. 1, p.141-155, jan./jun. 2004 
feita em campo, é a atenção que o jornal disponibiliza aos assuntos locais de cada município. A linha editorial do TodoDia é voltada para a informação regional, mas sem desprezar os assuntos locais, próprios de cada município. "O TodoDia nos Bairros (espaço aberto no caderno de Cidades para as reivindicações de moradores) é muito importante porque dá ao morador o direito de reivindicar. Às vezes, ele procura o jornal direto, porque através daquela reclamação ele tem uma resposta", afirma o vice-presidente da Federação Paulista das Associações de Moradores de São Paulo e presidente do Consab's (Conselho das Associações de Moradores de Sumaré), José Adilson Pereira dos Santos. ${ }^{18}$ Para o vice-prefeito de Hortolândia, Walter Bernardo (PSDB), o apoio aos eventos locais também valoriza a comunidade.

O padre Itamar Gonçalves, da tradicional Paróquia São Domingos, em Americana, enfatiza a preocupação do jornal TodoDia com os assuntos locais. "O TodoDia é um jornal que procura responder às necessidades das pessoas da cidade e da Região. É um jornal que fala de uma forma simples e direta, e esclarece a população. É uma cobertura bonita, que mostra o dia-a-dia da Região e ajuda as pessoas a formarem opinião. É um jornal reconhecido pela sociedade". ${ }^{19}$

$\mathrm{O}$ foco local também é voltado para os assuntos econômicos de cada cidade, como observa o presidente da Aciah (Associação Comercial, Industrial e Agropecuária de Hortolândia), Tercio Mascarenhas. ${ }^{20}$

\subsection{Canal de debate sobre a Região}

O jornal como incentivador do debate sobre as questões regionais é outro conceito levantado em campo pelos representantes dos principais segmentos da Região. Do ponto de vista da comunidade, ao veicular a informação regional, o TodoDia desperta na sociedade a consciência sobre a necessidade de debater os problemas em comum de forma regional. "Essa proposta de jornalismo regional atendendo a uma microrregião atua neste vácuo que há. É necessário um órgão que veicule notícias locais, notícias nacionais, mas que ao mesmo tempo dê ênfase a essas notícias da região. E isso eu acho que vai ao encontro também de uma tendência que está havendo de metropolização, de políticas metropolizadas, de metropolização de políticas públicas e isso requer também uma metropolização da notícia, da circulação da informação", afirmou o secretário de Educação e Cultura de Americana, Herb Carlini.

Comun. Inf., v. 7, n. 1, p.141-155, jan./jun. 2004 
Paulo Jodas, delegado seccional de Americana, que abrange as cidades de Santa Bárbara d'Oeste, Sumaré, Monte Mor, Nova Odessa, Hortolândia, Cosmópolis, Artur Nogueira e Engenheiro Coelho, fala sobre a importância da informação regional para área de segurança: "O conceito de jornalismo regional é muito importante porque estamos em uma região conurbada. Os processos, os problemas não podem ser tratados de forma isolada, individual. Eles têm de ser tratados de forma regional. O crime tem um interesse regional porque essa região é muito ampla, o espaço de circulação entre as pessoas é muito amplo. Então, não dá para dizer que o ladrão mora aqui e rouba ali. Isso tem um efeito comum a todos os locais. A comunicação ajuda as pessoas e elas têm o direito de saber o que acontece", afirmou Jodas.

\section{Considerações finais}

Um dos pilares da sociedade organizada é a informação. E quanto mais próximaa informação estiver da realidade do leitor, mais chances terá a comunidade de se organizar e fortalecer. O TodoDia foi criado em 1996 com o propósito de unir, por meio da comunicação, uma Região ligada geograficamente e politicamente. O conceito de jornalismo regional é adotado pelo TodoDia em diferentes ações. A aplicação do conceito de jornalismo regional é identificada em todo o processo de produção do TodoDia, mas é na redação, na linha editorial, que o jornalismo voltado para a Região formada por 14 cidades encontra um forte respaldo. Toda a produção jornalística é pensada com o objetivo de atender à Região, respeitando as características e os fatos locais que movimentam cada cidade.

Estudos e reflexões sobre jornalismo regional mostram que a informação é essencial para o desenvolvimento da comunidade. Após seis anos de atuação - primeiro em Americana, Santa Bárbara d'Oeste, Sumaré, Hortolândia e Nova Odessa, depois em Paulínia e mais recentemente em Holambra, Cosmópolis, Engenheiro Coelho, Santo Antônio de Posse, Pedreira, Monte Mor, Artur Nogueira e Jaguariúna - o TodoDia se fortalece como uma mídia regional e local, focada nos assuntos de interesse de 14 cidades dos 19 municípios que compõem a RMC (Região Metropolitana de Campinas).

Após analisar os conceitos de jornalismo regional e realizar entrevistas com integrantes de diferentes segmentos da sociedade de Americana, Santa Bárbara d'Oeste, Sumaré, Paulínia, Hortolândia e Nova Odessa, conclui-se que o TodoDia consolidou-se como uma Comun. Inf., v. 7, n. 1, p.141-155, jan./jun. 2004 
mídia referencial para essa Região não só porque tem sua linha baseada na informação regional, mas porque a comunidade se identifica e se reconhece nas páginas do TodoDia.

Ojornal obtém essa identificação da comunidade ao focar sua linha editorial na informação regional, sem desprezar o foco local, as características e as peculiaridades de cada município. Os leitores do TodoDia têm uma visão dos acontecimentos que movimentam seu município dentro do contexto regional em que cada cidade está envolvida. Essa identificação ocorre à medida que o jornal abre espaço para eventos, festas católicas, manifestações populares e reclamações de bairro. Uma festa de peão em Hortolândia pode não interessar à população de Americana, mas terá espaço nas páginas do TodoDia na medida em que despertar o interesse dos moradores de Hortolândia.

Ao levar a informação regional e local a seus leitores, o jornal estimula o debate dos problemas - e das soluções para os problemas - em nível regional. Com a criação da Região Metropolitana de Campinas, o debate entre os municípios passa a ser cada vez mais regional e freqüente. Com uma mídia voltada para a realidade desses 14 municípios, os leitores têm uma visão macro da realidade em que estão inseridos. A possibilidade de conhecer a realidade dos municípios vizinhos por meio de um único veículo de comunicação é uma das vantagens do TodoDia, de acordo com a pesquisa qualitativa. A circulação às segundas-feiras, o espaço voltado para as reclamações de moradores, a coluna TodoDia nos Bairros, a veiculação das notícias locais sem bairrismo, o texto enxuto e sem informações desnecessárias, além das reportagens aprofundadas sobre assuntos polêmicos, como a instalação da Usina de Carioba 2, em Americana, são os principais aspectos positivos do TodoDia, a partir do ponto de vista da comunidade em que o jornal está inserido.

Por outro lado, a mesma pesquisa aponta que a comunidade quer mais do jornal. Os pontos em que, segundo a pesquisa, o jornal precisa se aperfeiçoar se referem à entrega do jornal - para alguns representantes, o exemplar do TodoDia chegatarde emalgumas localidades.Acomunidade também quer reportagens locais mais aprofundadas. A pesquisa constatou que, na opinião da comunidade, com a ampliação da cobertura-em 2002 o TodoDia passou a cobrir mais oito cidades - houve uma redução do espaço destinado às matérias mais aprofundadas sobre a realidade de

Comun. Inf., v. 7, n. 1, p.141-155, jan./jun. 2004 
cada município. A comunidade quer mais notícia local e com maior profundidade, um indicador da importância do noticiário local, voltado para a realidade de cada município.

Ao oferecer a notícia regional com foco local, o jornal abre um canal para a população reivindicar, mostrar seus problemas e cobrar solução. Essa postura crítica não seria diferente com o jornal. A comunidade absorveu a importância de ter um veículo de comunicação preocupado com as necessidades regionais e locais, e por isso ela cobra mais espaço do jornal para os debates locais.

A campanha Vote Regional, que estimulou os eleitores a votarem em candidatos da região, e a série de reportagens em defesa da isenção de tarifas nas cabines de bloqueio instaladas em Nova Odessa são exemplos do que a conscientização e o fortalecimento da comunidade podem fazer. Hoje, a região tem mais representantes na Câmara dos Deputados e na Assembléia Legislativa e os moradores de cinco cidades da região têm acesso livre nas cabines de bloqueio instaladas em Nova Odessa. São conquistas de uma comunidade fortalecida por meio da informação e que encontrou respaldo em um veículo de comunicação comprometido com a informação local e regional.

\section{Abstract}

This work presents the research results carried through with members of diverse social segments on the relation between the newspaper TodoDia and its readers, with emphasis in the importance of the publication as an element of formation of a critical conscience and as instrument of manifestation of the local and regional community. The objective is to identify in what measure the communities of American, Saint d'Oeste Bárbara, Sumaré, Hortolândia, New Odessa and Paulínia, in the Interior of São Paulo, identify themselves with the periodical, the importance of this paper for these cities and the influence communities have in the periodical.

Keywords: Regional journalism; community journalism; information and regional development

\section{Referências}

DOWBOR, Ladislau. O que é o poder. São Paulo: Editora Brasiliense, 1999 (Coleção Primeiros Passos, 285).

Comun. Inf., v. 7, n. 1, p.141-155, jan./jun. 2004 
LOPES, Dirceu F. "A evolução do jornalismo em São Paulo”. Citado por MARTINS, Gerson. "Jornalismo Regional: das primeiras impressões ao fortalecimento da imprensa no interior". Em www.gersonmartins.jor.br/jornalismo_regional.htm. Visita realizada em 03/12/02.

MAIA, Vanessa. "Entre o texto, o autor e o leitor: uma questão de contrato". Em: Intercom - Sociedade Brasileira de Estudos Interdisciplinares da Comunicação XXV Congresso Brasileiro de Ciências da Comunicação - Salvador/BA - 1 a 5 Set 2002.

PAVANI, Cecília G.C. "Jornal regional: construção de cidadania". Em: Correio Popular, cad. Opinião, p.3, 18/11/2002.

VIEIRA, Toni André Scharlau. "Jornalismo no Interior-Potencialidades éticas e técnicas". Em: Intercom - Sociedade Brasileira de Estudos Interdisciplinares da Comunicação XXV Congresso Brasileiro de Ciências da Comunicação - Salvador/BA - 1 a 5 Set 2002.

\section{Notas}

${ }^{1}$ Contagem realizada pelo IVC em julho de 2002.

${ }^{2}$ Veículos de comunicação com sede em um dos seis municípios: Americana, Santa Bárbara d'Oeste, Paulínia, Sumaré, Nova Odessa e Hortolândia.

${ }^{3}$ Entrevista concedida em 24 de setembro de 2002.

${ }^{4}$ Entrevista concedida em 13 de novembro de 2002.

${ }^{5}$ Entrevista concedida em 24 de setembro de 2002.

${ }^{6}$ Entrevista concedida em 6 de novembro de 2002.

${ }^{7}$ Entrevista concedida em 31 de outubro de 2002.

${ }^{8}$ Entrevista concedida em 6 de novembro de 2002.

${ }^{9}$ Entrevista concedida em 10 de outubro de 2002.

${ }^{10}$ Entrevista concedida em 3 de outubro de 2002.

${ }^{11}$ Entrevista concedida em 16 de outubro de 2002.

${ }^{12}$ Entrevista concedida em 16 de outubro de 2002.

${ }^{13}$ Entrevista concedida em 9 de outubro de 2002.

${ }^{14}$ Entrevista concedida em 7 de novembro de 2002.

${ }^{15}$ Entrevista concedida em 13 de novembro de 2002.

${ }^{16}$ Entrevista concedida em 11 de novembro de 2002.

${ }^{17}$ Entrevista concedida em 31 de outubro de 2002.

${ }^{18}$ Entrevista concedida em 11 de novembro de 2002.

${ }^{19}$ Entrevista concedida em 7 de Novembro de 2002.

${ }^{20}$ Entrevista concedida em 5 de novembro de 2002.

Comun. Inf., v. 7, n. 1, p.141-155, jan./jun. 2004 